\title{
Collective action and Invasive Species Governance in Southern Arizona
}

Dr. Aaron Lien, University of Arizona School of Environment and Natural Resources

Dr. Elizabeth Baldwin, University of Arizona School of Government and Public Policy

Dr. Kim Franklin, Arizona-Sonora Desert Museum

Prepared for delivery at the Workshop on the Ostrom Workshop (WOW6) conference, Indiana University Bloomington, June 19-21, 2019. (C) Copyright 2019 by Elizabeth Baldwin

\section{Introduction}

Biological invasions - in which non-native species become established and outcompete native flora and fauna - is one of a number of emergent " $21^{\text {st }}$ century" environmental problems whose complex characteristics make it difficult for policy makers and practitioners to develop durable and effective management solutions. Invasive species management shares several characteristics with problems like land use change and the spread of contagions like Ebola and Zika. Their effects are often debilitating for human and ecological communities if left unaddressed, but there is uncertainty regarding the timing and extent of consequences. Changing climatic conditions can exacerbate the challenge of predicting the timing and severity of consequences, making it difficult to rally public support in favor of preventive action (Brenner \& Franklin 2017).

At the same time, many of these problems share characteristics that make collective action challenging. They tend to span jurisdictions, sectors, and governance levels. As a result, addressing them will generally require individual and collective action by heterogeneous actors who have divergent interests in prevention and mitigation, as well as different resources and capabilities to bring to bear on the problem. The actors who are most affected by a problem may not have the resources needed to mitigate it; and actors who are well-positioned to prevent or mitigate harms may have little reason to do so. Moreover, emergent problems that are new to a given jurisdiction may require cooperation between and among actors who have limited experience with each other, or there may be institutional and organizational barriers to effective cooperation.

Under these circumstances, traditional policy instruments and approaches - such as command and control, market-based, or community-based natural resource governance - are unlikely to achieve lasting, positive results. Instead, effective governance likely requires venues for cooperation and coordination that span jurisdictions and sectors, as well as a range of policy instruments that provide diverse actors with relevant incentives, motivation, information, and resources to undertake preventive action - before significant harms occur.

In this paper, we ask: how do existing and emerging governance arrangements encourage individual and collective action to manage invasive species? We focus our attention on a particular case - buffelgrass in the Sonoran Desert of southern Arizona. Like other $21^{\text {st }}$ century problems, invasive buffelgrass poses an imminent and significant threat to the region: if left unaddressed, it will outcompete native species, eventually causing an ecological state change that will fundamentally alter the character and function of the region's ecosystems; increase fire risk; undermine the tourism and outdoor recreation sectors of the southern Arizona economy; and reduce quality of life for citizens in the area. While ecologists and conservation biologists have long warned of the consequences of buffelgrass invasion, and while practitioners in the region have developed forums for information sharing and coordination, the diverse public and private land managers on the front lines of buffelgrass management have yet to undertake sufficient individual and collective action to keep the buffelgrass population in check. Here, we draw on 
interview data and archival documents to develop an in-depth case study of buffelgrass and buffelgrass management efforts in the region, and use the case to build theory about governance mechanisms that might prompt effective individual and collective action by land managers in the region.

This paper proceeds as follows. In the next section, we review current theoretical and empirical understanding of collective action, collective action dilemmas, and effective governance arrangements for overcoming collective action dilemmas. We then explain our research design, methods, and data, provide background on our case of invasive species in the Sonoran Desert of Southern Arizona, and present results from interviews and archival analysis. We then discuss our findings before concluding the paper.

\section{Literature Review}

Collective action dilemmas occur in situations where individual interests run counter to the common interests of a group of individuals (Baldwin et al. 2018; Olson 1965; Poteete et al. 2010). In classical terms, collective action problems tend to arise when it is not possible to exclude actors from using a particular good or service; under such circumstances, few private actors will have incentives to provide the good, regardless of the potential gains that could be realized from doing so (Ostrom 2003). Where such situations arise, there are potential gains that the group can realize if requisite actions are taken, but individual actors may face insufficient incentives undertake these actions (Ostrom 1990). Collective action dilemmas are not insurmountable, but addressing them will generally require the creation of some sort of governance arrangement - a policy instrument, an informal set of rules, a funding mechanism, a coordinating body - that changes individuals' incentives enough to prompt the requisite actions (Ostrom 1990). The particular governance arrangements needed will depend on the context at hand, including the nature of the collective action dilemma itself, the characteristics of the actors involved, and the information available about the problem.

Scholars often start their analysis distinguishing between collective action problems concerning rivalrous and non-rivalrous goods. When goods are rivalrous, one actor's consumption diminishes the amount available to others; where goods are non-rivalrous, one actor's consumption does not diminish the quantity available to others (Ostrom 2003; see Fig 1). Non-excludable and non-rivalrous goods present a classic collective action dilemma - the problem of public goods. The most commonly offered example of a public good is national defense. If any actor is able to provide the basic good - a country free from external invasion - it is impossible to exclude anyone else in-country from enjoying the same good, and one person's enjoyment does not diminish the good's availability to others (Ostrom 2003). Under such circumstances, unless there is an individual with sufficient resources and incentive to provide the good for all citizens, it will go unprovided unless the group can devise appropriate governance arrangements for its provision (Olson 1965).

\begin{tabular}{|l|l|l|}
\hline & Rivalrous goods & Non-rivalrous goods \\
\hline Excludable goods & Private goods & Toll goods \\
\hline Non-excludable goods & Common pool goods & Public goods \\
\hline
\end{tabular}

Table 1. Classification of public, private, common pool, and tool goods. Adapted from Ostrom 2003.

The typical solution to a public goods problem is public provision of the good, funded through taxation. Resolution of this kind of collective action problem thus relies largely on political support for realizing the public good, accompanied by appropriate governance arrangements for translating citizens' preferences into policy action. While public goods are nearly always funded by taxes and provided by government agencies, there are multiple possible arrangements for the actual production of public goods and services: they may be produced by private contractors, for example, or co-produced jointly between citizens and government actors. 
Public goods are not the only type of collective action dilemma, of course. Perhaps the best-studied collective dilemma concerns common pool resources, where one actor's use of a resource diminishes the quantity available for others to use, but where it is infeasible to restrict actors' ability to access and use resources (Ostrom 2003). Rational individuals will have an incentive to maximize their own use, inviting resource over-use and the "tragedy of the commons" (Ostrom 1990; Hardin 1968). With common pool resources, actors may be able to realize significant gains - e.g., long-term, sustainable enjoyment of the resource - if they can find a resolution to the collective action dilemma.

There are multiple potential solutions to common pool resource dilemmas. Policy scholars have long recognized that some common pool resource dilemmas may be resolved through privatization and the establishment of property rights (Dales 1968). Where privatization is not feasible, government regulation may be possible (Hardin 1968), although the effectiveness of regulatory approaches can be limited where government agencies lack full information about the resource system or adequate resources to monitor and enforce regulatory limits on resource use (Ostrom 1990). Under certain contexts, communities may be able to devise locally-appropriate rule systems that are as effective - if not more effective - than regulation by external authorities (Acheson 1990; Ostrom 1990). Ostrom (1990) examines the rules and rule systems used in long-enduring, community-based natural resource governance systems, and concludes that several approaches to rules are correlated with success. These include rules that limit users' ability to appropriate a resource, using locally-appropriate limitations on the time, location, or extent of appropriation; and appropriate systems for monitoring and sanctioning rule violations (Ostrom 1990). In addition to these operational rules that shape individual behavior, Ostrom recognizes that effective community-based natural resource management also requires appropriate collective choice rules that outline how operational rules may be changed, and constitutive rules that create the governance system itself and delineate how collective choice decisions will be made. In communities that have devised effective solutions to CPR dilemmas, resource users have been able to participate in determining collective choice and constitutive rules that govern the system.

The above discussion - and much of the empirical work to date on collective action - has focused on public goods and common pool resources in their purest forms. In practice, however, collective action dilemmas are often more complex than suggested by the two-by-two matrix presented in Table 1 . Excludability, for example, may not always be a simple binary characteristic; some goods may be excludable at very high costs, and other goods may change from excludable to non-excludable after technological, legal, or other changes. In addition, any given policy problem might well present multiple connected collective action dilemmas. With novel environmental problems like invasive species, for example, scientific information about potential impacts to a given ecological system may be a public good in and of itself; and collective action to prevent or mitigate these impacts may not be possible until some actor undertakes and shares appropriate scientific research. Scholars have thus argued that problems like species invasion can contain elements of both public goods and common pool resource dilemmas (Marshall et al. 2019).

Moreover, there are other factors beyond the nature of the good that add to the complexity of the collective action dilemma and that shape the range of potentially effective solutions. Most existing empirical studies of common pool resource systems, for example, have focused on groups of resource users, who all share reliance on the resource system at hand, contribute to resource over-use, share common knowledge of system attributes, and have the capability of taking action to limit resource overuse (e.g., Ostrom 1990). But for emergent problems like species invasions, there may be little overlap between the set of actors who contribute to the invasion, the set of actors who are harmed by it, the set of actors who understand the ecological impacts of the invasion, and the set of actors who have the capability to redress the problem. Where the underlying collective action dilemma is complex and spans multiple distinct sets of actors, appropriate governance solutions will likely need to be similarly complex. 
Scholarship on appropriate governance solutions for this type of complex collective action problem is nascent and there is limited systematic empirical evidence about how to best resolve such problems. Polycentricity scholars theorize that when collective action dilemmas span jurisdictions, sectors, and governance levels, effective governance arrangements will also need to span jurisdictions, sectors, and governance levels (McGinnis 2005; Baldwin et al. 2018). Structurally, governance arrangements will need to bring together and encourage coordination between actors with a shared interest in resolving the collective action dilemma at hand (Baldwin et al. 2018). If some of these actors are not interested or willing to participate in governance, coercive instruments, such as regulatory mandates, may be necessary (Baldwin et al. 2018; McCord et al. 2017). In some cases, action to redress the problem itself may be contingent on the development and dissemination of scientific research, or the development of appropriate policy venues for coordination and collaboration among relevant actors; each of which may present its own collective action problem (Baldwin et al. 2018). Effective resolution of complex collective action problems may thus require an array of solutions that effectively provide and disseminate information; constitute forums for policy decision making; and provide heterogeneous actors with incentives to engage in governance and to commit to appropriate actions.

In this paper, we build on Marshall et al. (2019) to analyze whether and why collective action has occurred in a particular case of invasive species management. We use empirical observation to better understand the nature of the collective action problem; the relevant actors that contribute to, are affected by, understand, and have resources to mitigate the problem; the relevant interests of these actors; and the way that existing efforts to address the invasion have (or have not) shaped actors' incentives to take actions that redress the problem.

\section{Research Design, Methods, and Data}

The purpose of this paper is to understand how existing and emerging institutional arrangements for invasive species management promote or undermine collective action a) between government agencies in a given region and $b$ ) between government and non-government actors in a given region. We chose Pima County in Southern Arizona as a study location for several reasons. First, the area is threatened by buffelgrass, an invasive species that, if left unchecked, will displace the native Saguaro cactus - which in turn will subject the region to significantly greater fire risk, reductions in ecotourism, ecological harms, and reduced quality of life. The saguaro-dominated landscape is thus a public good, providing fire regime stability and a basis for sustained ecosystem functioning and ecotourism in the region. While the benefits of collective action to provide this public good are clear, however, the region includes a wide range of public and private landowners, and practitioners have struggled to convince these landowners to undertake individual and joint actions that would contribute to the provision of a public good. Finally, actors in Pima County have been engaged in efforts to promote collective action on buffelgrass since roughly 2008, using a range of institutional approaches; efforts continue and new institutional arrangements are continually emerging. ${ }^{1}$ Pima County thus provides an ideal case to examine how different institutional arrangements have - or have not - encouraged different types of individual and joint action to address buffelgrass, and to theorize about institutional arrangements that might lead to desired results.

Our approach is qualitative. We conducted interviews and archival research to understand how existing institutional arrangements promote or discourage collective action for buffelgrass mitigation between land management agencies in southeastern Arizona. We conducted interviews with key stakeholders and analyzed archival data related to current and past attempts at coordinated buffelgrass mitigation. Here, we

\footnotetext{
${ }^{1}$ One of this study's co-authors has been involved in several of these efforts.
} 
review our case study and study region, and the approach and methods for interviews and archival data analysis.

\subsection{Case Description}

Buffelgrass is a warm-season bunchgrass native to Africa. It was introduced to southern Arizona, Texas, northern Mexico, and other regions around the world for its drought tolerance relative to native bunchgrass species and its ability to withstand moderate to heavy grazing by cattle and other livestock. With these benefits also come challenges. Buffelgrass is a fire adapted species native to African savannah ecosystems, while many of the places where it has been introduced are fire intolerant desert scrub ecosystems. This is certainly true for the study region, Pima County, AZ.

Pima County is located in southeastern Arizona (Figure 1). Southeastern Arizona is characterized by a varied topography that promotes high plant and animal biodiversity. Tucson, AZ is the only major urban center in southeastern Arizona. It is located in a desert valley at the base of two mountain ranges, the Santa Catalina Mountains and the Tucson Mountains. The valley floor and lower slopes of these mountains up to about 1,200 meters are characterized by a Sonoran Desert scrub ecosystem. This ecosystem consists of cactus, small desert trees such as palo verde and ironwood, woody schrubs, and some sparsely distributed grasses. Native Sonoran Desert scrub is highly fire resistant and wildfires are generally not a common form of disturbance in the system. The iconic giant saguaro cactus is also endemic to the Sonoran Desert scrub. Saguaro cactus are of critical importance culturally and economically in southeastern Arizona. Indigenous peoples in the region harvest saguaro fruit as a part of their traditional diet. Saguaro's are also the primary reason for the designation of Saguaro National Park, which draws tourists to the region.

With the introduction of buffelgrass, the Sonoran Desert scrub and saguaro cactus are under threat. Buffelgrass has two major impacts on the ecosystem. First, because it is highly drought tolerant and grows in dense patches, it can out compete native flora for scarce water resources. Buffelgrass typically responds more quickly to rainfall than native grasses and requires less rainfall to initiate growth at the beginning of the growing season. Southern Arizona experiences a bimodal rainfall regime with about half of the precipitation arriving in the form of intense thunderstorms in the summer and the other half arriving during the winter months. Unlike many native warm season grasses, when rainfall is adequate, buffelgrass will grow and reproduce in both the summer and winter rainy seasons. These characteristics allow it to outcompete native grasses and shrubs and allow it to develop monocultures or near monocultures over large patches of desert scrub.

Second, buffelgrass is fire tolerant rather than intolerant. When dry during the fall and sprint dormant seasons, it is highly flammable. This characteristic, when combined with its ability to grow in dense patches, allows buffelgrass to carry fire across an otherwise fire-resistant landscape. While a large fire has not occurred in the study region since the introduction of buffelgrass, many experts see such an event as inevitable if buffelgrass is allowed to persist and spread across the landscape. The impacts of a landscape scale fire would be significant. Saguaro cactus and other desert adapted plant species are fire intolerant. The introduction of landscape scale fire is expected to cause an ecological transition from a desert scrub plant community to a buffelgrass dominated desert savannah, including significant reductions or complete loss of saguaro cactus. While the latter is likely a resilient system given southeastern Arizona's climate, it would come at the cost of the current ecosystem, which is also resilient absent the influence of buffelgrass. 


\begin{tabular}{|l|}
\hline Table 2: Specific Actors \\
Policy Actors: \\
National Parks Service, \\
Bureau of Land Management, \\
US Fish and Wildlife Service, \\
US Forest Service, \\
Department of Defense, \\
Tohono O'dham Nation, \\
Pascua Yaqui Tribe, \\
AZ State Lands Department, \\
AZ State Parks, \\
AZ Dept. of Transportation, \\
Pima County, \\
City and County Parks Depts., \\
Pima County Dept. of \\
Transportation, \\
Cities and towns regionally \\
\\
Economic actors: \\
Homeowners' associations, \\
Land developers, \\
General public \\
Community actors: \\
Non-governmental \\
organizations
\end{tabular}

The invasion of buffelgrass in southeastern Arizona takes place within a complex institutional and policy context. There are a variety of policy actors present within the study region. Land owners and managers in the region include federal agencies, the National Parks Service (NPS) and the US Forest Service (USFS); Pima County and various county departments, e.g. Parks and Natural Resources, Transportation, and Flood Control; the City of Tucson and its various departments; private individuals; homeowners associations (HOAs); and others (Table 2). In some cases these actors are wholly independent of others. For example, the NPS and USFS operate according the federal laws, rules, and policies and Pima County and the City of Tucson have no explicit power to regulate or directly influence management decisions on federally owned lands. Similarly, the NPS and USFS have no power to regulate adjacent county or privately-owned lands. In both of these examples, however, decisions made by the managers on neighboring properties can affect the likelihood of buffelgrass's continued spread across the landscape.

This diversity of independent and sometimes overlapping decision centers coupled with the need for regional coordination to effectively mitigate buffelgrass invasion highlights the need for regional scale collective action among diverse actors operating in different institutional settings. For example, HOAs must follow city and/or county regulations, but may also independently set their own regulations or rules about how, when, and how frequently individual landowners within the HOA must mitigate buffelgrass invasions within the boundaries of the HOA. The very nature of the buffelgrass problem, and similar invasive species issues, also suggests that a polycentric governance approach could improve management

outcomes by encouraging the development of rules and norms between independent actors that result in collective action to address a species invasion. When an invasive species is capable of rapid spread at a landscape scale, it is likely that collective action is required to contain or eradicate a species after its arrival and initial spread across a landscape.

\subsection{Key Informant Interviews}

We conducted key informant interviews with three agencies in the study region: Pima County Parks and Natural Resources Department (hereafter Pima County), the NPS, and the USFS. We selected these agencies because they are proportionally the largest land owners in the study region. Each agency also has an active buffelgrass mitigation program and a long history of participation in buffelgrass mitigation activities.

We interviewed three key informants at each agency. Key informants were selected based on the advice of co-author Franklin and the position of each informant in the structure of the target agency. Franklin is the convener of the Sonoran Desert Cooperative Weed Management Association, a new effort in the study region to develop a forum for inter-agency coordination on invasive species management, and has years of experience working with agencies throughout the study region as lead invasive species scientist for the Arizona-Sonoran Desert Museum. Informants ranged from high ranking agency leaders with the ability to set policy within an organization, to field level personnel who implement agency policy on a day-to-day basis. 
Interviews followed a semi-structured format. Questions were developed around the following research themes: 1) organizational structure and invasive species management fit within the organization 2) perceived impacts of buffelgrass on native ecosystems 3) approach to and level of success with buffelgrass management 4) buffelgrass management policy and management program structure 5) relationship with outside entities in regard to buffelgrass management. All questions were open ended and qualitative. Interviews ranged from approximately 40 minutes to nearly 2 hours in length. All interviews were conducted by an interviewer and a notetaker. Interviews were also recorded to ensure the accuracy and detail of notes. The study design and methods were reviewed and approved by the University of Arizona Human Subjects Protection Program (\#XXXXX).

Following each interview, the notes and recording were transcribed for analysis. We used an inductive, thematic coding approach to analyze interview transcripts. We began by establishing five general themes corresponding to our research themes and coding each interview into these five broad categories. We then developed more specific sub-themes based on individual responses. For example, to address research theme one, organization structure and invasive species management fit within the organization, we coded the role of the individual within the organization (leadership, middle management, field level), data about the overall management focus of the organization (general resource management, conservation, preservation, environmental education), and data about how invasive species fit into the overall organizational structure (primary focus, secondary focus, uncertain). In each of these sub-themes, summary data was recorded to enable interpretation of results. Finally, after coding each interview data from all informants from a given organization, we produced a synthesis summarizing the responses relative to our research themes.

\subsection{Archival Data Analysis}

To understand forums for collective action between organizations interested in buffelgrass management, we collected organizational bi-laws and other foundational documents for past and present organizations intended to enable regional management of buffelgrass in the study region. There were three such organizations: the Southern Arizona Buffelgrass Coordination Center (SABCC), a now defunct nongovernmental organization; the Buffelgrass Working Group (BWG), a consortium of organizations interested in buffelgrass management; and the Sonoran Desert Cooperative Weed Management Area (SDCWMA), a new organization focused on management of buffelgrass and other invasive species in southeastern Arizona. Here, we focus on the BWG and SDCWMA because they were explicitly created as venues for collective action, while $\mathrm{SABCC}$ was an independent organization that played a coordinator role for the BWG.

We used the Institutional Analysis and Development (IAD) framework's rule typology to identify and classify the type and effect of rules structuring interactions between organizations involved in the BWG and the SDCWMA. Institutions are the rules, strategies, and norms that people use to structure and organize repeated interactions. Here, we are interested in how the rules for BWG, and SDCWMA, respectively, influenced collective action between agencies in the study region. We collected the bi-laws for each organization, coded rules by type, and analyzed how these rules structured interactions between agencies responsible for buffelgrass management. We first coded individual rules and then qualitatively summarized the overall effect of each rule type. For example, to code payoff rules, we read the bi-laws for each organization, identified individual payoff rules using basic aim verbs as indicators, and then summarized the cumulative effect of these payoff rules on interactions between agencies. We used individual rules to model action situations and summaries of rule types to understand overall patterns of interactions.

\subsection{Synthesis of Archival and Interview Data}


To address our research questions of how existing and emerging institutional arrangements promote or undermine collective action between government and non-government actors and across levels of governance, we synthesize our archival and interview data understand how internal institutional arrangements drive individual agency management and shape engagement in policy venues designed to enable collective action between organizations. This synthesis had two main steps: synthesis of interview and institutional data and mapping of networked action situations. At this point we make no determination of the quality or effectiveness of collective action relative to buffelgrass management. While buffelgrass eradication efforts have not succeeded, as of this analysis these efforts are ongoing. We do assess the longevity of collective action and analyze how alignment or misalignment of institutional arrangements within and between actors affect the persistence of collective action over time.

First, we jointly analyzed interview and institutional data to identify matches and mismatches between individual agency's self-reported institutional arrangements for buffelgrass management and the institutional arrangements of the BWG and SDCWMA. Here, we seek to identify alignment and/or misalignment between the expectations of participating agencies and the structure of venues for collective action. Where there is significant alignment, we expect greater engagement in a given policy venue. Second, we construct maps of linked action situations implied by the institutional arrangements of policy venues for collective action and compare these networked action situations with interview data reporting on interactions between agencies. These data allow us to assess the degree to which policy venues for collective action are influencing actual behavior of managers.

\section{Results}

We present our results in three sections: how individual actors' motivations to address buffelgrass are influenced by factors internal to their given organization, institutional analysis of policy venues for collective action, and synthesis of interview and institutional analysis results to explain the impact of past venues for collective action on buffelgrass mitigation and suggest lessons for emerging collective action venues.

\subsection{Internal factors influencing individual actors}

\subsubsection{Basic attributes and biophysical conditions of actors}

Saguaro National Park - The NPS was established by Congress in 1916 with a mission to "conserve the scenery and the natural and historic objects and the wildlife therein and to provide for the enjoyment of the same in such manner and by such means as will leave them unimpaired for the enjoyment of future

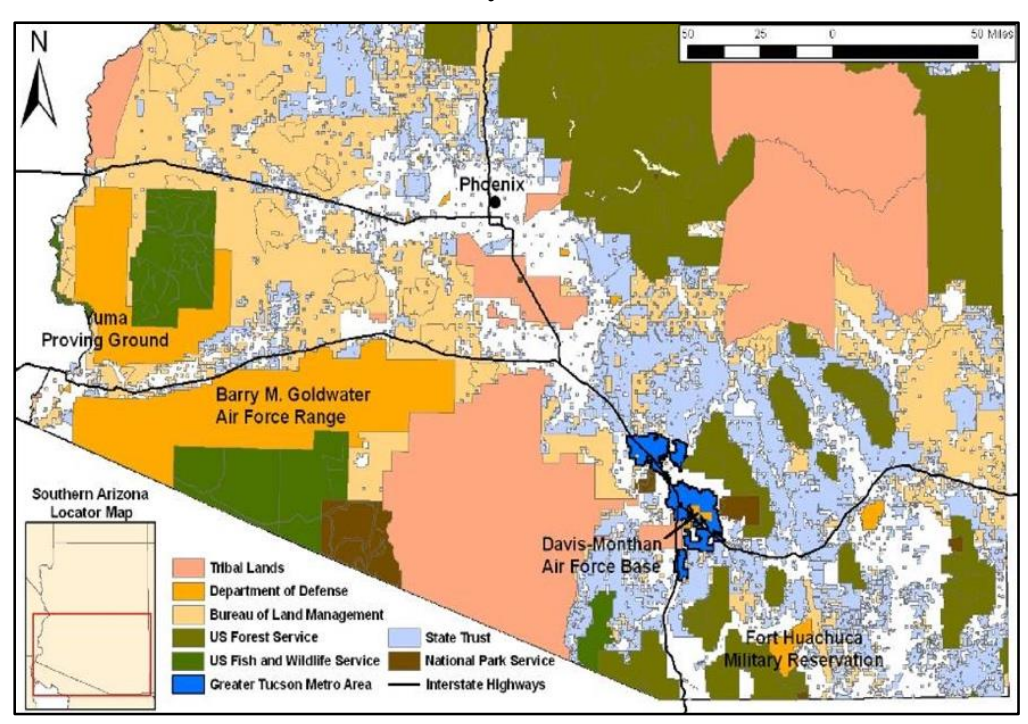
generations." This mission sets the NPS apart from other US federal land management agencies in that the NPS is tasked with maintaining natural areas as they are for future generations rather than enabling sustained use of land and resources by a range of users. The NPS's resource conservation mission is reflected in the legislation establishing each national park, including Saguaro National Park (SNP). Saguaro National Park was initially designated as a national monument by presidential proclamation in 1933, with explicit reference to the extraordinary natural 
values present in the areas included in the monument and their need for preservation. The proclamation calls for the protection of "giant cactus," because of their "outstanding scientific interest." The national monument was created out of lands belonging to the USFS Coronado National Forest; the proclamation makes specific reference to the differences in management mandated for monument lands relative to the prevailing management of the national forest: "any use of the land which interferes with the preservation or protection as a national monument is hereby forbidden."

\section{Figure 1: Study Area}

Over time, the monument was expanded to include large land holdings both east and west of the city of Tucson, AZ (Figure 1). The monument was officially converted to a national park by Congress in 1994, at which time the most recent expansion of the park took place. Today, the total area of the park is approximately 37,000 hectares. The east portion of the park is over twice the size of the west unit. The overall mission of the park - to maintain the unique resource values, specifically saguaro cactus, was not changed. The east and west portions of the park vary significantly in geography and ecosystems present. The east unit of the park is larger and more geographically and ecologically diverse, with elevations ranging from 750 meters to over 2,500 meters. Saguaro cactus and buffelgrass are only found on the lower slopes of the Rincon Mountains up to approximately 1,300 meters. The west unit of the park ranges in elevation from 700 meters to approximately 1300 meters. As a result, saguaro cactus and buffelgrass are capable of growing virtually anywhere in the park unit. Between both park units, SNP receives approximately one million visitors per year and is a significant contributor to the Tucson, AZ economy.

Coronado National Forest - The overall mission of the USFS is quite different from that of the NPS. The USFS mission is stated in policy in the agency's Organic Act of 1897, “...for the purpose of securing favorable conditions of water flows, and to furnish a continuous supply of timber for the use and necessities of citizens of the United States." This mission was affirmed in the Multiple Use Sustained Yield Act (1960) and the National Forest Management Act (1976), both of which establish rules the USFS must follow in timber, range, and general resource management. Beyond specific legal mandates, the USFS also has a strong cultural tradition of multiple use management that can be traced back to the first chief for the USFS, Gifford Pinchot. Pinchot espoused a conservation ethic grounded in a utilitarian view of sustainability, "...the greatest good for the greatest number in the long run," that has held such sway in the culture of the agency throughout its history that its official centennial film and book are titled The Greatest Good. Multiple use policies and tradition are clearly reflected in the interview results.

The Coronado National Forest is one of the most diverse national forests in the US due to its unique configuration. Unlike most national forests, the Coronado is not one contiguous block of land. Instead, it is made up of disconnected islands of forest found on successive north-south trending mountain ranges across southeastern Arizona (Figure 1). These mountain ranges are administratively organized into ranger districts, with each ranger district typically responsible for one or two mountain ranges. The forest boundary for each district is typically on the lower slopes of a given mountain range. This results in the presence of ecosystems ranging from Sonoran Desert scrub to sub-alpine pine woodlands at the highest peaks. Elevations range from approximately 700 meters to 3000 meters. Like SNP, buffelgrass is found at lower elevations on mountain slopes surrounding the Tucson metropolitan area coincident with saguaro cactus. Unlike SNP, many districts of the Coronado have no or very little buffelgrass. Most of the suitable habitat for buffelgrass in its current range is found in the Santa Catalina District, which borders Tucson.

Pima County Natural Resources, Parks and Recreation - The parks department in Pima County, AZ is unique. In addition to owning and operating urban parks throughout the county, Pima County also owns thousands of hectares of natural areas and ranchland. The natural areas are managed similarly to national parks - for conservation and preservation of natural resources for the enjoyment and education of the public. Ranchlands were purchased throughout the county to maintain rural character, prevent urban sprawl, provide habitat for wildlife, and to support the regionally important cultural heritage of ranching. The natural areas program, which includes the natural areas and ranchlands, developed over time through 
the adoption of taxpayer funded bonds to purchase land and through the implementation of an agreement with the federal government for the protection of threatened and endangered species.

While buffelgrass is found on county owned lands throughout the Tucson metropolitan region, Tucson Mountain Park is the center of both buffelgrass invasion and mitigation efforts by the county. Tucson Mountain Park is a natural area west of Tucson. It shares a boundary with the western unit of SNP and covers the southern portion of the Tucson Mountains. Between SNP and Tucson Mountain Park, the vast majority of the Tucson Mountains have protected status. The topography and plant communities are also shared with SNP west. Tucson Mountain Park was established for similar reasons as SNP - to protect outstanding and important natural resources, including saguaro cactus, and to provide for recreation. Therefore, the county sees addressing the threat posed by buffelgrass to saguaros as central to its management responsibilities and mission for Tucson Mountain Park.

Other Actors - In addition to the major land management agencies profiled above, there are several other important agencies and landowners that are important to the success of buffelgrass mitigation efforts in the region: the Arizona State Land Department; land developers; other city, county, and state departments and agencies; and home owners associations (HOAs). While we did not interview representatives from these actors as a part of this research, we comment on their general role in regional buffelgrass mitigation.

The Arizona State Land Department own thousands of hectares of land in the study region. These lands were given to the State of Arizona at statehood by the federal government and are held in trust by the state for the benefit of public education and other trustees. State lands are highly diverse. In the study region, they tend to cluster in the valleys surrounding the Tucson metro area. The State Land Department prioritizes two land uses: development and livestock grazing, as they are seen the maximize the economic returns on trust land to the trustees. There is a therefore a direct linkage between land developers and the State Land Department. New development in the Tucson metro area often takes place on land purchased from the State Land Department because trust lands are often available in large blocks, enabling large development projects. Buffelgrass does occur on both state trust lands and land owned by developers or undergoing development. Disturbance of land as a result of the development process may also favor establishment of buffelgrass by removing competition from native plants.

Other city, county, and state agencies are also either directly engaged with invasive plant management, own land affected by buffelgrass invasion, may affect the spread of buffelgrass in carrying out day-to-day activities, or regulate land use through enforcement of rules and ordinances. For example, roads are a potential vector of spread for buffelgrass across the landscape. Decisions about weed control along highway and roadway rights-of-way can influence the spread of buffelgrass to adjacent lands owned by the NPS, USFS, Pima County, etc. While few of these actors are significant landowners, their participation in collective action for buffelgrass mitigation is likely important at a landscape scale. County and city departments that make and enforce land use regulations and ordinances, for example weed control ordinances, can also have an impact on invasive species spread beyond government owned land. It is, however, beyond the scope of the current study to assess the impact of existing ordinances and code enforcement activities on buffelgrass control by actors such as developers, HOAs, and individual homeowners.

Homeowners associations are a unique actor. They set and enforce rules that apply to small areas of land within the study area, but typically own or directly control only a small amount of land themselves. Therefore, the actions taken by HOAs are a reflection of the interests of their members - the homeowners in a given development. Homeowners Associations are common in the suburban areas surrounding Tucson. As such, they are often located on the edges of the urban area at the interface with natural Sonoran Desert ecosystems where buffelgrass and saguaro cactus are common. 


\subsubsection{Effect of buffelgrass on individual actors}

All interviewees reported that their agency is negatively impacted by buffelgrass, with most citing similar concerns about the effect of buffelgrass on native Sonoran Desert ecosystems. The common theme was that buffelgrass changes ecosystems by increasing fire risk, changing plant community composition, and directly threatening the long-term persistence of saguaro cactus. Interviewees from SNP directly tied mitigation and eradication of buffelgrass to the agency's overall mission of preserving natural resources "unimpaired" for future generations. Pima County interviewees had a similar perspective, noting its mission to protect the resources in Tucson Mountain Park as a natural preserve for county residents and saguaros as a resource important to the county's tourism economy. Interviewees from the USFS provided slightly different responses. While clearly recognizing the ecological impact of buffelgrass on USFS managed lands, it was also clear that buffelgrass is just one priority out of many. This stands in contrast to an SNP respondent who stated, "Buffelgrass is the number one priority of Saguaro National Park." Importantly, buffelgrass occurs on only a small portion of the USFS lands in the study area and the USFS also has many other invasive plants species on its lands and significant recreation and fire management responsibilities.

\subsubsection{Internal resources available to each actor}

The NPS has more staff per land area managed than of other agencies studied and has devoted significant staff resources to managing buffelgrass on SNP lands. Saguaro National Park has as many as seven staff who work on buffelgrass management and mitigation, plus additional volunteers and interns. The NPS also has both a regional and national team focused on non-native plant issues, so the management of invasive species has strong support throughout the organization. Pima County has staff that have invasive species management as part of their formal duties. These staff members are also responsible for other land management duties within the natural areas program, but are able to devote significant time to buffelgrass mitigation, especially in Tucson Mountain Park. In contrast, the USFS has no staff dedicated to invasive species management. Instead, invasive species management is an "ancillary duty" of the range management staff in one forest district. As a result, there is one staff person working on the buffelgrass problem and this person can only dedicate limited resources.

All three agencies face challenging funding environments that limit their ability to carry out an effective buffelgrass mitigation program. While SNP and the USFS generally have funds available for buffelgrass treatment each year, the timing of this funding is inconsistent. The certainty of funding is higher for SNP than for the USFS; the CNF has no permanent budget for invasive species treatment and instead must compete with other priorities on an annual basis. While the forest has been successful in past years, uncertainty surrounding funding is an impediment to developing a more robust treatment program. Saguaro National Park reports generally reliable funding based on priorities established by staff. The USFS, because of its lack of staff resources, also relies on outside contractors to carry out buffelgrass mitigation work, which creates a second step delaying translation of monetary resources into action onthe-ground. In past years, Pima County had funding allocated to buffelgrass treatment, but this support has declined and county resources are now limited to staff resources and occasional funds for contractors.

\subsubsection{Contribution of each actor to buffelgrass mitigation}

Of the agencies included in this study, SNP has the most comprehensive and well supported buffelgrass management program. The reasons for this are largely attributable to the mission and structure of the NPS and SNP, as opposed to a particular heightened interest in buffelgrass or greater recognition of the problem relative to other actors. The NPS has a mission directly oriented at resource preservation rather than resource use or management. All SNP interviewees described the primary mission of the park as protecting saguaro cactus and associated plant communities. As a result, at the organizational level SNP has a strong motivation to act on buffelgrass mitigation that exceeds what is seen with the USFS and Pima County. However, this commitment to management on its own lands does not appear to extend to neighboring jurisdictions. While one interviewee mentioned the Southern Arizona Weedwackers (SAW), 
a volunteer organization focused on buffelgrass mitigation and eradication, as a partner organization and the SAW mention the park, the other interviewees did not mention the existence of an ongoing relationship. In fact, two of the three interviewees specifically noted that the NPS does not work across boundaries. As a result, relative to other actors, SNP has a robust eradication program focused on removing buffelgrass from areas popular with tourists and destroying large patches of buffelgrass within the park's interior using aerial spraying of herbicide from helicopters. Depite this, SNP interviewees report that they are losing ground and that buffelgrass continues to expand in the park.

The USFS and Pima County have a range of responsibilities largely focused on resource use and management rather than protection. While staff recognize buffelgrass is a problem, because it is not prioritized by the organization, management efforts are described as "treading water" or "trying to keep up." Interviewees reported that the forest is losing ground due to limited resources and bureaucratic challenges with applying management resources on-the-ground. What management does take place does not apply innovative techniques or involve coordination with other actors across boundaries. This is in spite of CNF sharing boundaries with SNP and several large HOAs. The USFS does accept volunteer assistance when possible, but limited staffing resources makes this difficult. Relative to the USFS, the county places a high priority on invasive species treatment, but does not have the same level of resources as the NPS to back up this interest. The county has been a leader in the region over time in both buffelgrass treatment through the SAW volunteer program and its role in coordinating other actors in the region and encouraging cooperation for more systematic treatment of buffelgrass.

Despite the county's interest and leadership in the past, this has not translated into effective buffelgrass treatment over time. County leaders generally perceive buffelgrass as a persistent problem and do not think the mitigation program is making a significant difference in the spread or persistence of buffelgrass in the county. Despite this, leadership does support ongoing efforts to treat for buffelgrass in areas prioritized by staff and is working to develop new systems, e.g. a digital database and remote sensing, to improve prioritization. The county made a significant regional contribution by taking a leadership role in early coordination efforts, which resulted in the approval of aerial spraying for the NPS. The county provided funding and land to test aerial spraying when federal actors had neither the money nor the ability to implement a test program due to the need for an environmental assessment under the National Environmental Policy Act (NEPA) before aerial spraying could take place. The county pilot program provided the data needed to complete the NEPA process. However, no other entities beyond the NPS, including Pima County, have been able to use aerial spraying due to the cost involved. Since the program to gain approval for aerial spraying ended in the early 2000s, coordination activities seem to have waned somewhat, but are still a priority of the county.

\subsubsection{Summary of institutional arrangements for individual action}

Saguaro National Park, the USFS, and Pima County all operate in different institutional settings. These differences result in both barriers and opportunities for individual and collective action to address buffelgrass invasion on their own lands and regionally. While both federal agencies, the institutions structuring decision making in SNP and CNF at the local level are quite different. These differences are the result of both the formal regulations that establish the rules the actors follow in implementing their invasive species programs and the agency traditions that have developed over time.

The interview results clearly show differences in agency tradition and institutions between the USFS and the NPS. The USFS is hierarchical in structure, with institutions and traditions that reinforce this hierarchy. Management decisions in the CNF are driven by a combination of regulatory requirements, national and regional priorities, and how these priorities trickle down to the forest districts through the CNF leadership and the forest plan, which guides decision making at the forest level. Staff priorities are set primarily at the district level in response to direction from the forest supervisor's office and the forest plan. At all levels, staff seek to balance management to benefit multiple uses, including recreation, 
wildlife, grazing, and timber. The result of these formal and informal institutions is deprioritization of buffelgrass treatment in favor of other priorities dictated by regulations as interpreted by district-level managers and the forest plan. There are clear regulatory requirements the USFS must meet in administering grazing allotments, but there are no specific requirements for invasive species management. The forest plan class for limited treatment on USFS lands, but acknowledges that the recommended level of treatment will not stop the expansion of buffelgrass on forest lands. The overall result is weak internal incentives for action to mitigate buffelgrass

In contrast to the USFS, the NPS and SNP's traditions and institutions work to enable internal action on buffelgrass. Interviewees described the park and the agency in general as less rigid and less hierarchical than the USFS. Individual parks are given more flexibility to address unique resource management challenges. Priorities for treatment are set by local staff consistent with the mission of the park. This fits with an agency culture that is focused on preservation of resources in parks as they are today. In the case of SNP, this includes efforts to mitigate the impacts of buffelgrass. Saguaro National Park staff work together to establish local priorities for management, including buffelgrass, and these recommendations are generally followed by leadership when funds are allocated. The park superintendent has consistently supported buffelgrass treatment.

Both the NPS and USFS are subject to NEPA. As a result, major actions undertaken by the agencies to mitigate buffelgrass must follow NEPA rules. Of particular importance in the NEPA process are information rules - rules that establish how and when information is exchanged between the agency carrying out the NEPA process and other actors, including the public. While SNP has navigated the NEPA process to enable aerial spraying of buffelgrass with the assistance of Pima County, the USFS has not gone through this process and sees NEPA as a barrier to individual action. The USFS has a long history of contentious NEPA processes, general uses its own staff to complete NEPA requirements, and is frequently sued by outside actors that claiming inadequate analysis of environmental impacts or violations of process rules. The NPS does not share this history. As a result, NPS was willing to go through the NEPA process to enable aerial spraying while the USFS was not.

Pima County's institutional setting is different from that of the federal agencies. Over time, the county has established a program that is internally focused on mitigating the impacts of buffelgrass on Tucson Mountain Park through the use of community volunteers. The institutions supporting this program seem to be largely the result of tradition and the influence of external actors on county decision makers during the 1990s and early 2000s. The county continues its treatment program, not because it is required to, but because personnel think it is consistent with the mission of Tucson Mountain Park and because personnel think it is important to maintain current desert ecosystem generally.

\subsubsection{Barriers to collective action}

The biophysical conditions of each actor and their respective levels of interest in buffelgrass mitigation result in a hypothesis that collective action to address the threat posed by buffelgrass to all actors is likely. Natural resources valued by each actor are threatened by buffelgrass, namely saguaro cactus and the associated Sonoran Desert scrub plant community. The USFS, SNP, and Pima County each recognize the threat posed by buffelgrass to this valued resource and interviewees with each agency expressed that buffelgrass mitigation was at least a moderate priority, and for SNP and Pima County it was a high priority. And finally, all actors face serious resource constraints that may be aided by combining efforts and leveraging limited resources in a coordinated mitigation plan. However, significant barriers to collective action result from misalignment of each actors' internal institutional arrangements and attributes (Table 3).

These barriers are reflected in the disparity of financial resources available to each actor. Funding challenges are related to two issues: 1) institutional rules controlling how funding is allocated and the 
processes that must be followed to spend money and 2) consistency of funding over time. The USFS struggled with problems related to the allocation of funding from higher levels of bureaucracy and contracting requirements for paying outside entities. The CNF could not rely on funding to arrive at the time it is needed to effectively treat buffelgrass at the optimum time of year to kill plants. In addition, because buffelgrass requires retreatment for as many as five years, consistent funding is needed over time, which has often not been the case. Rules for contracting with external service providers were also a significant impediment to utilization of available financial resources. Contraction regulations often slowed the issuance of contracts to the point where ideal treatment windows had already passed. Pima County faced similar issues, with inconsistent funding and difficult contraction rules that required selection of inexperienced landscaping contractors rather than companies with wildland weed control expertise. In contrast, while SNP's funding was by no means assured, interviewees felt the program was relatively stable on a year-to-year basis, which allowed them to implement a consistent treatment program.

Differences in the attributes of actors, especially agency tradition, and institutional structures also appear to impair consistent coordination between actors. All actors are most focused on treatment on their own lands and fulfilling their own agency missions - preservation for SNP and Pima County and multiple-use management for the USFS. With limited exceptions, each agency appears content to continue work on its own lands with limited coordination with others. Saguaro National Park and Pima County are facing what interviewees regard as overwhelming buffelgrass challenges on their own lands and have not done much to look beyond their own treatment programs to a regional coordination strategy. Interestingly, though Pima County's perception is that they enabled the development and implementation of a specific treatment approach on NPS lands - aerial spraying of herbicides using a helicopter-by providing funding and testing on county lands, this contribution was entirely unacknowledged by NPS. It has either been forgotten, or there are significant differences in how SNP and Pima County view their contributions to the development of this treatment technique. County respondents also report a relatively high amount of coordination and cooperation with other actors, though it is unclear how formal these arrangements are. County respondents report working with other organizations on volunteer efforts, to share equipment and expertise, and to plan eradication strategies on lands with a common boundary. While field staff report the existence of formal MOUs, leadership staff did not mention any formal administrative mechanisms between the county and other actors.

Form the interviews there is no indication that the CNF is interested in or would have the capacity to engage in transboundary cooperation with other entities. There is also limited evidence that the forest regards buffelgrass as a particular management priority relative to the many other challenges it faces. This is clearly a reflection of informants understanding of the multiple use mandate and tradition of the USFS. They see buffelgrass as just one management challenge among many. More pressing challenges to ensuring forest health and ensuring long-term use and enjoyment of the forest by the public include range management to prevent ecosystem degradation and fire prevention and management to prevent large scale fires. Finally, overall management direction comes from national and regional offices; the USFS is highly hierarchical and the lack of engagement in invasive species management locally is in part a reflection of the priority the national and regional offices of the USFS place on invasive species management relative to other multiple use goals.

Table 3: Summary of Individual Actors and Barriers to Action

\begin{tabular}{|l|l|l|l|l|l|}
\hline & SNP & CNF & Pima County & HOAs & Developers \\
\hline $\begin{array}{l}\text { Org. attributes/ } \\
\text { biophysical }\end{array}$ & Preservation & Multiple use & Preservation & Diverse goals & Economic/ \\
conditions & mission; park & mission; forest & mission; parks & $\begin{array}{l}\text { set by member } \\
\text { profit- }\end{array}$ \\
& has significant & is dominated & have & landowners; & maximization \\
& biological & by uses and & significant & many border & goal; may \\
parks or forest & border parks \\
\hline
\end{tabular}




\begin{tabular}{|c|c|c|c|c|c|}
\hline & $\begin{array}{l}\text { buffelgrass } \\
\text { invasion }\end{array}$ & $\begin{array}{l}\text { resources that } \\
\text { are not } \\
\text { threatened by } \\
\text { buffelgrass }\end{array}$ & $\begin{array}{l}\text { resources and } \\
\text { buffelgrass } \\
\text { invasion }\end{array}$ & $\begin{array}{l}\text { and have } \\
\text { buffelgrass } \\
\text { management } \\
\text { issues }\end{array}$ & $\begin{array}{l}\text { or forest; } \\
\text { buffelgrass } \\
\text { thrives with } \\
\text { disturbance }\end{array}$ \\
\hline $\begin{array}{l}\text { Effects of } \\
\text { buffelgrass on } \\
\text { org. }\end{array}$ & $\begin{array}{l}\text { Harms Sonoran } \\
\text { Desert plant } \\
\text { communities } \\
\text { with fire and } \\
\text { competition }\end{array}$ & $\begin{array}{l}\text { Harms } \\
\text { Sonoran } \\
\text { Desert plant } \\
\text { communities } \\
\text { with fire and } \\
\text { competition }\end{array}$ & $\begin{array}{l}\text { Harms } \\
\text { Sonoran } \\
\text { Desert plant } \\
\text { communities } \\
\text { with fire and } \\
\text { competition }\end{array}$ & $\begin{array}{l}\text { Increased fire } \\
\text { risk but may } \\
\text { be considered } \\
\text { aesthetically } \\
\text { pleasing }\end{array}$ & $\begin{array}{l}\text { Increased fire } \\
\text { risk but may } \\
\text { be considered } \\
\text { aesthetically } \\
\text { pleasing }\end{array}$ \\
\hline $\begin{array}{l}\text { Resources for } \\
\text { individual } \\
\text { action }\end{array}$ & $\begin{array}{l}\text { High relative to } \\
\text { other actors; } \\
\text { staff and } \\
\text { financial } \\
\text { resources } \\
\text { generally } \\
\text { available each } \\
\text { year }\end{array}$ & $\begin{array}{l}\text { Low relative } \\
\text { to other actors; } \\
\text { no dedicated } \\
\text { staff or } \\
\text { funding }\end{array}$ & $\begin{array}{l}\text { Low/moderate } \\
\text { relative to } \\
\text { other actors; } \\
\text { limited staff } \\
\text { and } \\
\text { inconsistent } \\
\text { funding }\end{array}$ & $\begin{array}{l}\text { Unknown; } \\
\text { resources } \\
\text { would need to } \\
\text { come from } \\
\text { internal } \\
\text { volunteers or } \\
\text { budgets }\end{array}$ & $\begin{array}{l}\text { Unknown; } \\
\text { contribution of } \\
\text { resources may } \\
\text { affect } \\
\text { profitability }\end{array}$ \\
\hline $\begin{array}{l}\text { Contribution } \\
\text { to buffelgrass } \\
\text { mitigation }\end{array}$ & $\begin{array}{l}\text { Comprehensive } \\
\text { program using } \\
\text { staff and } \\
\text { volunteers; } \\
\text { invaded areas } \\
\text { increasing }\end{array}$ & $\begin{array}{l}\text { Limited } \\
\text { program using } \\
\text { contractors } \\
\text { and occasional } \\
\text { volunteers; } \\
\text { invaded areas } \\
\text { increasing }\end{array}$ & $\begin{array}{l}\text { Moderate } \\
\text { program using } \\
\text { staff and } \\
\text { volunteers; } \\
\text { report success } \\
\text { in Tucson } \\
\text { Mountain Park }\end{array}$ & Unknown & Unknown \\
\hline $\begin{array}{l}\text { Org. } \\
\text { institutional } \\
\text { arrangements }\end{array}$ & $\begin{array}{l}\text { Flexibility to } \\
\text { address unique } \\
\text { resource } \\
\text { issues; subject } \\
\text { to NEPA rules }\end{array}$ & $\begin{array}{l}\text { Hierarchical } \\
\text { with goals set } \\
\text { by national } \\
\text { and regional } \\
\text { offices; } \\
\text { subject to } \\
\text { NEPA rules }\end{array}$ & $\begin{array}{l}\text { Responsive to } \\
\text { community } \\
\text { interests and } \\
\text { concerns but } \\
\text { limited } \\
\text { internal } \\
\text { flexibility; not } \\
\text { subject to } \\
\text { NEPA rules }\end{array}$ & $\begin{array}{l}\text { Variable based } \\
\text { on individual } \\
\text { HOA codes, } \\
\text { covenants, and } \\
\text { restrictions; } \\
\text { subject to } \\
\text { local } \\
\text { ordinances }\end{array}$ & $\begin{array}{l}\text { Variable based } \\
\text { on developer/ } \\
\text { corporate } \\
\text { structure; } \\
\text { subject to local } \\
\text { ordinances }\end{array}$ \\
\hline $\begin{array}{l}\text { Barriers to } \\
\text { individual } \\
\text { action }\end{array}$ & $\begin{array}{l}\text { Preservation } \\
\text { mission on its } \\
\text { own lands } \\
\text { results in an } \\
\text { internal focus }\end{array}$ & $\begin{array}{l}\text { Contracting } \\
\text { rules for } \\
\text { external } \\
\text { service } \\
\text { providers; } \\
\text { inconsistent } \\
\text { funding; lack } \\
\text { of } \\
\text { organizational } \\
\text { interest }\end{array}$ & $\begin{array}{l}\text { Preservation } \\
\text { mission on its } \\
\text { own lands } \\
\text { results in an } \\
\text { internal focus, } \\
\text { but has shown } \\
\text { most interest } \\
\text { in external } \\
\text { coordination }\end{array}$ & Unknown & Unknown \\
\hline
\end{tabular}

\subsection{Past, current, and emerging venues for collective action}

By the mid-2000s, it was becoming abundantly clear to federal land managers and conservation biologists that buffelgrass posed a serious threat to the sustainability of the Sonoran Desert landscape. Moreover, it was also clear that individual land managers' efforts to address buffelgrass would not be sufficient to 
address the problem. Actors in the region have developed or initiated a number of policy venues and forums to increase coordination and cooperation on buffelgrass, described in greater detail below. These efforts have met with mixed successes: actors in the region have cooperated - and some continue to cooperate - on scientific research, information sharing, and public outreach, with some significant success in building scientific understanding of buffelgrass treatment options and increased public awareness. And on limited occasions, actors working individually or collectively have been able to secure funding for buffelgrass eradication projects of interest that align with federal wildfire prevention objectives. But these injections of federal funds have been short-lived, particularly since President Trump's election in 2016, which halted many federal environmental protection initiatives. When this article was written in 2019, cooperative efforts in the region had for some time focused largely on information-sharing and strategic planning, while individual land managers either struggled to address the problem with inadequate funding and resources (as in the case of SNP, CNF, and Pima County), or simply chose not to take action (as in the case of HOAs and developers).

\subsubsection{Past venues for collective action: the Buffelgrass Working Group (BWG)}

This section focuses on the BWG, the first formalized effort to promote collective action in the region. In 2006, an informal coalition of agency representatives, non-profit organizations, city and county leaders, and university researchers met with the goal of improving buffelgrass management across jurisdictions (BWG 2008). The more formal Buffelgrass Working Group (BWG) was established later that year, comprising core members of the informal coalition as well as organizations who had contributed financially to buffelgrass management efforts through the Cooperative Ecosystem Study Unit (CESU). Members signed a formal MOU that outlined the BWG's purpose and structure, as well as each members' obligations. The BWG became the primary regional venue for collective action to mitigate the impacts of buffelgrass. In this section we provide a short summary of the rules and other institutional arrangements that structure the BWG and its work, followed by a discussion of what the organization has achieved - the outputs of collective action.

BWG Constitutive Rules - The BWG MOU provides a clear statement of the group's scope and purpose, which are to enable the parties to 1) cooperate on development of management objectives; 2) facilitate effective response actions to control invasive species; 3) restore natural communities through coordinated invasive species management; and 4) facilitate funding from multiple sources (BWG 2008, Appendix 2). The organization is broadly inclusive; the focus is on the Santa Cruz river basin and MOU signatories include Arizona land management agencies, city governments, regulatory agencies, research organizations, and non-profit organizations. However, there are no rules or barriers to new members joining the group. The MOU also constitutes a basic structure for decision making and implementation. A steering committee is established and given responsibility for drafting strategic plans as well as annual operating plans. The steering committee has the authority to convene BWG members, develop and assist in implementing best management practices for invasive species management, and engage in advocacy on behalf of the group (BWG 2008). Each signatory to the MOU is allowed (but not required) to provide a representative to the steering committee.

$B W G$ Collective choice rules - The BWG Strategic Plan provides limited information about how decisions are made within the organization. Changes to the MOU itself require consensus among all MOU signatories; any MOU signatory may propose changes in writing, and proposed modifications become effective upon signature by all parties to the MOU. Within umbrella of the MOU, sub-groups of signatories are authorized to negotiate and enter into smaller MOUs as necessary; such MOUs would similarly require agreement of all involved parties. There are no formal rules specifying how decisions are made within the BWG steering committee or among the larger group of MOU signatories, although in practice decisions are made by consensus of all parties after negotiation and deliberation. 
$B W G$ Operational Rules - While the scope of the BWG includes information sharing, coordination, and encouraging individual and joint mitigation actions, the operational rules focus almost entirely on members' responsibility to share information with other MOU signatories. Members are required to share information about their individual buffelgrass management activities and are expected to work with other members to jointly produce information about buffelgrass extent, ecological effects, and management techniques. Members are also expected to meet at least annually to review progress on achieving objectives, identify strategic cooperative priorities for the upcoming year, and determine whether the MOU should be modified. Significantly, the MOU rules do not require members to undertake any specific actions beyond sharing information. Similarly, the MOU does not include any provisions related to monitoring, enforcement, or sanctioning members for noncompliance with rules.

Collective action outcomes- While the BWG's scope included strategic planning, finding funding, and engaging in ecological response and restoration, the group's successes have largely focused on strategic planning. The BWG's initial priority was to prepare a five-year strategic plan for proactive buffelgrass management, which was released in 2008 (BWG 2008). While the Strategic Plan itself might be considered a collective action outcome, the plan also identified twelve management goals that the group should work together to produce to minimize buffelgrass spread and impacts in the region. The group's success at achieving these collective action outcomes have been mixed. Below we review the evidence about the outcomes of collective action under the BWG.

Organizational, leadership, and partnership goals.

Three of the BWG's goals relate to the organization and coordination of efforts to address buffelgrass: 1 ) Maintaining the BWG as an advisory group; 2) identifying a non-profit organization that could serve as a focal point for information dissemination, coordinating volunteers, and acting as a fiduciary agent to receive and distribute funds in accordance with the BWG's strategic priorities (BWG 2008; Brenner \& Franklin 2017); and 3) identifying and providing information to partners to facilitate their implementation of buffelgrass management. These collective action outcomes have been at least partially achieved. Shortly after the strategic plan was issued, actors in the region raised sufficient funds to incorporate the Southern Arizona Buffelgrass Coordination Center (SABCC) to undertake this work. SABCC hired a full-time director who facilitated communication and coordination across agencies. But SABCC lacked long-term funding, and in 2016, the organization was dissolved and its functions were assumed by the Sonoran Desert Museum, a local conservation and outreach nonprofit. Both the BWG and the Sonoran Desert Museum remain active in providing advice and information and coordinating volunteer and other efforts in the region. There was also partial success in the development of information to facilitate buffelgrass mitigation in the region. The US Geological Survey and the University of Arizona, both members of the BWG produced several scientific tools for understanding the spread of buffelgrass in region and prioritizing treatment efforts. However, these models were only partially adopted by land managers. The plan also called for systematic mapping and database development to track buffelgrass invasion and treatment. While individual members adopted their own systems, a shared system was never created.

Legislation, Codes, and Ordinances

The BWG has made partial progress on two goals: first, to increase awareness of buffelgrass among state and national legislators, and second, to assist local jurisdictions in amending or developing new ordinances for buffelgrass control. BWG members were able to bring attention to the buffelgrass problem at both the state and national levels. The Arizona legislature in 2005 added buffelgrass to the state's noxious weed list, a legislative change that enables - but does not require - state and local jurisdictions to take action to eradicate buffelgrass. Less progress has been made in prompting local jurisdictions to adopt buffelgrass ordinances, however. Pima County has an ordinance on the books that allows the County to monitor properties in unincorporated areas of the county. When properties are infested with noxious weeds, county code enforcers are authorized to require landowners to remove the plants. The ordinance 
provides at least one local example of how local codes could work to address buffelgrass infestations on private lands, but it is not clear that the ordinance is enforced, and the ordinance currently applies only in unincorporated parts of the county.

BWG members have also had partial success in bringing federal attention to the problem. Interviewees with the NPS noted that federal officials within the agency are aware of the crisis. In its early years, SABCC was able to secure a $\$ 3.4$ million disaster mitigation grant from the Federal Emergency Management Agency to clear buffelgrass near Tucson International Airport and other critical infrastructure (Brenner \& Franklin 2017), and more recently Saguaro National Park received funding from the Department of the Interior's Wildland Fire Resilient Landscapes (WFRL) program, a short-lived Obama-era effort to fund multi-jurisdiction, land-scape scale wildfire planning (Brenner \& Franklin 2017). The project provided funding for scientific research, strategic planning, and eradication in key areas throughout the region. The WFRL program was terminated after the Trump administration took office, and funding from the program ended in 2017. BWG members thus have had some success in obtaining federal funding, but these efforts have provided one-time, short-term injections of funding and have not provided stable, long-term resources needed to maintain eradication efforts.

\section{Education, Outreach, and Volunteer Programs}

Two of the BWG's strategic goals focused on public outreach, expanding public understanding of buffelgrass's impacts on the community and increasing awareness of volunteer opportunities to assist with eradication efforts. Interviewees widely acknowledged the success of these efforts, noting that community members are knowledgeable about buffelgrass and that many volunteers are involved in eradication efforts. For example, SAW carries out volunteer buffelgrass pulls every month and has done so for over 10 years. The USFS reported that HOAs in areas bordering the forest have raised concerns about the presence of buffelgrass on nearby portions of the forest, which has resulted in the forest including these areas in its mitigation planning. All actors reported that buffelgrass is recognized by members of the general public as a problem. However, some also raised concerns that fatigue has set in for some in the community. The BWG and its members have promoted the threat of buffelgrass to saguaros for over 20 years, but the expected impacts, especially buffelgrass fueled wildfires, have yet to materialize, potentially undermining outreach efforts.

\section{Buffelgrass Treatment Strategies}

Two of the Strategic Plan goals focused directly on treatment strategies. Goal \#8 states that "public and private land owners and managers should protect life, property, and natural and cultural resources by preventing, controlling, and reversing the spread of buffelgrass." (BWG 2008, Exec Summary at viii.) There is limited evidence that BWG members have taken this set of actions, individually or collectively. The actor who has been most active - and proactive - in controlling buffelgrass spread, SNP, currently lacks sufficient resources to treat all parts of the park that are infested with buffelgrass. Other federal land managers similarly have insufficient resources to fully manage buffelgrass on their lands. There has been little, if any, concerted effort to address buffelgrass on private lands.

More progress has been made on goal nine, documentation and evaluation of buffelgrass treatment programs in the region. A cooperative arrangement between Pima County and SNP provided experimental evidence about the effectiveness and cost-effectiveness of different treatment options, from hand pulling to hand spraying to helicopter spraying.

Research and Planning

The final three goals from the BWG Strategic Plan include 1) making decision support tools available to all land managers; developing contingency plans to protect vulnerable areas from wildfire risk due to buffelgrass; and obtain scientific data on the effects of buffelgrass control on local ecosystems. Here, partial progress has been made and is ongoing. Researchers with the USGS have developed decision 
support tools that have been shared with public land managers in the region, although it is not clear that all land managers are currently using these modelling tools as a basis for their buffelgrass management decision making. Pima County has included buffelgrass in its wildfire risk planning, identifying areas that may be particularly vulnerable to wildfire due to heavy buffelgrass infestation. And ongoing collaborative efforts between the Sonoran Desert Museum and the University of Arizona continue to make progress on understanding how post-treatment land management affects ecological restoration. The BWG has thus been at least partially successful at integrating buffelgrass into regional research and planning efforts.

\subsubsection{Emerging collective action efforts}

In 2018, the Sonoran Desert initiated an additional forum for collective action - the Sonoran Desert Cooperative Weed Management Area (CWMA). CWMAs are an approach to invasive plant management that were devised in Idaho in the late 1990s, when state and federal land managers began to recognize invasive aquatic weeds as a threat to regional ecological health whose management would require cooperation across a wide range of landowners and other actors with a stake in managing invasive plants. Since then, CWMAs have formed across the US. CWMAs typically serve as a platform for relevant actors to share information and other resources and engage in region-wide strategic planning. CWMAs also encourage and facilitate the creation of MOUs between CWMA members, allowing members to formalize agreements about actions that each member will take, as well as how resources will be developed, used, and shared among members. Today, the BWG is defunct and the emerging SD-CWMA is the primary policy arenas in which multiple actors interact and engage in - or work towards - collective action to manage buffelgrass in Pima County.

\subsection{Synthesis: individual and collective action for buffelgrass mitigation}

The results of our interviews with SNP, the USFS, and Pima County provide data on both contemporary actions by these organizations to mitigate buffelgrass and their impressions on regional collective action to manage buffelgrass over time. Here, we synthesize the interview results and the institutional analysis of the BWG to identify areas of effective and ineffective coordination and offer explanation for why collective action formed around certain activities but not others. In summary, we find evidence of successful collective action to share information on the science and impacts of buffelgrass within the BWG and with the general public in the region did take place, but limited evidence that existing arrangements like the BWG prompted coordinated buffelgrass mitigation efforts that would not have otherwise occurred. The difference in outcomes are attributable to the complex nature of invasive species as a collective action problem and dissimilar internal institutional arrangements, attributes, and biophysical settings of each actor.

At the time of this study, collective action on buffelgrass mitigation was near its historical low point. The BWG had stopped functioning and the emerging SDCWMA, which in many ways was intended to fill the void left by the BWG, had been formed but was in the very early stages of identifying the scope of its work, the actors who would be involved, and the group's immediate priorities. This moment of lack of regional coordination was evident in the interviews, with most respondents focused on their own agency's lands and responsibilities and making only limited reference to ongoing work with other organizations. Despite this, the effects of past collective action on information sharing and public engagement is clear in the buffelgrass mitigation programs of each agency and the attitudes of the interviewees. Each agency recognized a significant increase in public awareness about the problems posed by buffelgrass and credited the BWG and/or the related SABCC in achieving this goal. It was also clear that all interviewees clearly understood the threat of buffelgrass to Sonoran Desert plant communities, regional economic development, and the built environment. All entities were using information developed through the BWG process on the approaches to buffelgrass eradication, namely repeated herbicide spraying or manual pulling over a period of at least five years to kill plants, seedlings, and the seed store in the soil. Pima 
County specifically noted its role in enabling helicopter spraying by SNP as a marquee example of what was possible through regional coordination on science and management information.

Significantly, collective action to share information and scientific findings about management of buffelgrass did not challenge any of the agencies' traditions or internal institutional arrangements. None have rules restricting participation in information sharing about management with other agencies or the public. In fact, the USFS and SNP have specific rules under NEPA and other laws that require information sharing. Other actors that were members of the BWG, including the USGS and the University of Arizona also had specific scientific and information sharing missions that were directly supported by engagement in the BWG. Therefore, collective action to share information had a relatively low barrier of entry for the agencies involved.

In contrast, despite clear goals established by the BWG strategic plan, collective action to engage in coordinated mitigation efforts across different land ownerships ran into barriers of differences in agency attributes (preservation vs. multiple use missions and traditions; locally generated management priorities vs. priorities generated by national and regional policy makers and regulations) and agency institutional arrangements (the process of allocation of funds, staffing levels, contracting rules, etc.). Each agency had strong incentives to ensure as much buffelgrass mitigation took place on its own lands as possible. This limited their ability to engage in coordinated regional action that would potentially direct management resources away from one agency in favor of another. Limited collective action on management did occur in unique circumstances when the benefits of collective action outweighed the costs. The primary example of this was the WFRL initiative. In this instance, in order to receive funding, SNP needed to work with the CNF to develop a regional project. Collective action in this case was enabled by a specific need of one actor that enlarged resources for multiple actors.

Beyond the demands placed on each agency to meet internal management goals, lack of staff resources severally constrained the ability to engage in collective action. The USFS has never had dedicated invasive species staff. The scale of the problem on SNP lands demands its staff focus inward rather than outward. Pima County at one time was the most engaged in regional coordination efforts, but over time as the problem persisted and major ecological consequences did not emerge, high level interest seemed to wane somewhat and staffing resources declined. Lack of staff at the USFS and Pima County has resulted in both relying on contractors to carry out work, with significant resources devoted to navigating the contracting process rather than engaging with other entities to coordinate activities. Surprisingly, even where agencies shared boundaries - a circumstance that would seem to encourage collective action because of the likelihood that buffelgrass would spread from one agencies land to the others-little to no collective action was reported.

The BWG strategic plan ultimately did little to encourage collective action for management because of its lack of payoff rules related to monitoring and enforcement of stated goals and strategies. In the case of information sharing, all actors recognized the benefits they received and valued these benefits enough that monitoring and enforcement was not needed. To motivate collective action for buffelgrass management, actors did not recognize individual benefits relative to perceived costs to organizational missions and overcoming internal institutional barriers. Without sufficient incentives, monitoring, and enforcement of goals, no actor was willing to sacrifice potential short-term buffelgrass expansion on their own land in return for the prospect of better long-term outcomes.

Each of these outcomes relates to the unique types of collective action problems invasive species mitigation presents. Invasive species and their management have characteristics of both public goods and common pool resources. Information about the science and management of invasive species is a public good. Information sharing does not increase the cost or diminish the effectiveness of developing information that is otherwise also required for individual action. By sharing information, the likelihood of 
successful invasive species eradication only increases. As a result, there are few barriers to sharing information. This is especially true for public agencies with explicit mandates to share information and scientific data with the public. Invasive species themselves are extractive users of a common pool resource - the natural environment in a given place. In our case, buffelgrass is a user of Sonoran Desert scrub plant communities. It diminishes the value of this community for other users, carrying out this activity without reference to the human institutions that have developed for the use and management of these resources. Therefore, institutions that enable treatment of natural resources as private goods - the land tenure system that divides the landscape and the institutional arrangements structuring the activities of the individual landowners - are undermined. Invasive species are a common pool resource problem within a setting that treats the common as a private good. Existing institutions are ill prepared for this unanticipated problem. In our case study, actors were not able to adapt internal institutions designed for inward focused management to address a multi-vector, landscape-scale problem demanding coordination across boundaries. The result of this collective action failure is continued spread of buffelgrass and its continued use of additional resources while siloed, inward-focused resource managers struggle to locate and eradicate new infestations.

\section{Conclusion}

Effective management of buffelgrass, invasive species generally, and many other emerging $21^{\text {st }}$ century resource management problems requires collective action across heterogeneous organizations. In the case of buffelgrass invasion in southern Arizona, many actors are interested in mitigating the impacts of buffelgrass on native Sonoran Desert scrub plant communities, but differences in the attributes of actors, institutional arrangements guiding their behavior, and the complexity of the problem have limited the development of long-term, effective collective action venues and institutions. Careful consideration of invasive species management as a collective action problem reveals that mitigation of buffelgrass presents multiple, nested collective action problems involving different types of public goods or common pool resources.

Prevention of arrival of buffelgrass into an ecosystem involves both a common pool resource - the ecosystem threatened - and a public good - information about the arrival of buffelgrass in new locations. At this early stage, additional impediments to collective action include lack for recognition of the problem, information asymmetries between actors who recognize the problem and begin to investigate mitigation measure and those who have yet to experience or recognize the problem, and lack of resources to mitigate a heretofore unknown threat. Each of these barriers presents a unique collective action challenge, the details of which are beyond the scope of this research, as buffelgrass was already established in the research area at the time we began our study.

After arrival and initial establishment of an invasive species threat, the collective action challenge continues to grow. To effectively mitigate an aggressive species such as buffelgrass, actors must work together on the coordination, gathering, and sharing of information related to mitigation; coordination of mitigation activities across jurisdictions; and development of institutions to ensure agreed to mitigation activities are undertaken on different land ownerships. These coordination and cooperation challenges continue to involve the same public and common pool resources - information and the degradation of valued native ecosystems. Our research shows that heterogeneous actors can work together to develop institutions that can address the public good information sharing problem, though there are challenges with sustaining these institutions when collective action for mitigation fails to develop. Actors cooperate to share information because they all benefit. Each actor gains resources that improve their ability to achieve their internal goals, without risk of violating internal institutional structures. Ultimately, however, internal institutions come to undermine this collective action as actors attempt to move from information sharing to addressing the core of the problem - mitigation on-the-ground. In the case of buffelgrass, while actors were able to establish institutions that included mitigation strategies and norms, the lack of payoff 
rules resulted in little coordinated action. Overtime, this also came to undermine collective action around information sharing.

The key challenge then becomes identifying the mechanisms that will allow heterogeneous actors to overcome internal barriers to coordination to enable collective action to maintain the common pool resource of shared ecosystems. This is the next step in our research. Approaches to solving this problem most include improved knowledge of internal institutional structures and the opportunities and barriers they present to collective action, the preferences of heterogeneous actors when presented with models of future ecosystem conditions absent coordination, and the factors that prevent individuals within different organizations from following through on commitments to participate in collective action institutions.

Together, improved knowledge of the relationships between these factors may provide new approaches to proactive management of emerging $21^{\text {st }}$ century resource management challenges, from invasive species to emerging diseases. 


\section{References}

Acheson, J. M. (1988). The lobster gangs of Maine. Upne.

Baldwin, E., McCord, P., Dell'Angelo, J., \& Evans, T. (2018). Collective action in a polycentric water governance system. Environmental Policy and Governance, 28(4), 212-222.

Brenner, J. C., \& Franklin, K. A. (2017). Living on the Edge: Emerging Environmental Hazards on the Peri-Urban Fringe. Environment: Science and Policy for Sustainable Development, 59(6), 16-29.

Dales, J. H. (1968). Pollution, Property and Prices

Hardin, G. (1968). The tragedy of the commons. Science, 162(3859), 1243-1248.

Olson, M. (1965). The logic of collective action: Public goods and the theory of groups. Cambridge, MA: Harvard University Press.

Ostrom, E. (1990). Governing the commons: The evolution of institutions for collective action. Cambridge, UK: Cambridge University Press.

Ostrom, E. (2003). How types of goods and property rights jointly affect collective action. Journal of theoretical politics, 15(3), 239-270.

Marshall, G. R., Coleman, M. J., Sindel, B. M., Reeve, I. J., \& Berney, P. J. (2016). Collective action in invasive species control, and prospects for community-based governance: The case of serrated tussock (Nassella trichotoma) in New South Wales, Australia. Land Use Policy, 56, 100-111.

McCord, P., Dell'Angelo, J., Baldwin, E., \& Evans, T. (2017). Polycentric transformation in Kenyan water governance: A dynamic analysis of institutional and social-ecological change. Policy Studies Journal, 45(4), 633-658.

McGinnis, M. (2005). Costs and challenges of polycentric governance. In Workshop on Analyzing Problems of Polycentric Governance in the Growing EU. Berlin: Humboldt University.

Poteete, A., Janssen, M., \& Ostrom, E. (2010). Working together: Collective action, the commons, and multiple methods in practice. Princeton, NJ: Princeton University Press. 